\title{
USING POPULAR CULTURE TO DEVELOP STUDENTS' MEDIA LITERACY AND CRITICAL THINKING SKILLS
}

\section{Valentina Gavranović}

Singidunum University,

Belgrade, Serbia

Correspondence:

Valentina Gavranović

e-mail:

vgavranovic@singidunum.ac.rs

\begin{abstract}
:
This paper addresses the ever-growing complexities pertaining to information consumption, which are particularly enhanced by the advancement of technology. It focuses on the essential skill which is needed nowadays for an effective navigation in digital age - media literacy. This paper investigates how the core concepts of media literacy can be applied in the analysis and evaluation of media products, with the aim to promote and develop students' media literacy and critical thinking skills, as well as their digital competence. The purpose of this work is to present the process and the results of a project conducted among secondary school students which focused on the use of popular culture as a resource for the application of the key media literacy concepts and principles.
\end{abstract}

Keywords:

media literacy, five key concepts, popular culture, technology-mediated, critical thinking.

\section{INTRODUCTION}

Technology has become an integral part of almost every segment of human activity, and the ever-changing processes affecting social and cultural relations also influence many aspects of education, resulting in various new or redefined theoretical concepts. One of them is, undoubtedly, the redefinition of media literacy, which casts a new light on the scope of traditionally perceived notion of literacy and what it means to be literate in the $21^{\text {st }}$ century.

For the last couple of decades not only has media literacy gained in importance in the sphere of social sciences, but also it was introduced in educational context, and was defined as one of the key skills to be developed in the classes, or even introduced as a separate subject in many school systems around the world. According to the Law on the Education System Foundations of the Republic of Serbia, in 2018 media literacy was incorporated within an optional subject called 'Jezik, mediji i kultura' (Language, Media and Culture), taught in grammar schools, and legal documents regulating all aspects of education also state that media literacy is one of the key skills to develop in the classroom through all subjects [1]. 
Closely related to medial literacy is the notion of critical thinking skills, and these two are often studied together because being media literate implies having well developed critical thinking skills. In terms of legal documents which regulate education and its aspects, critical thinking skills are defined as the key skills teachers need to aim at developing while planning their lessons [1].

This paper focuses on a project initiated by the Fulbright Teaching Excellence and Achievement Programme the author of this paper was a part of during the academic year 2019/2020. This project, drawing on the knowledge and experience the author gained at the training programme called Media Literacy, held at the Kent State University, the USA, was conducted among secondary medical school students in Belgrade. The aim of this study is to reflect on the theoretical framework related to media literacy and its core concepts, and to suggest how they can be incorporated in the syllabus, through a description of the conducted projects and its results. The empirical part of this study reveals the results related to students' awareness of media literacy and its main principles, and how they apply them in their studies and everyday life. Another part of the research provides pedagogical principles arising from the results obtained from the project organised in English language classes, incorporating media literacy core concepts, and focusing on the use of popular culture as a resource for the application of these principles.

\section{BEING LITERATE IN THE $21^{\text {ST }}$ CENTURY}

The context wherein we teach today is much more complex and diverse than ever before, and the aims of teaching have also been modified; in order to support $21^{\text {st }}$ century learners and their needs, 'a multiplicity of discourses' must be negotiated in pedagogy [2].

In traditional terms, literacy is defined as the ability to read and write. However, as the complexities of the nature of reading texts and the channels we get them are growing, the scope of literacy is being expanded as well. Over time, the perception of literacy was modified and started to include a variety of skills needed for a proper and functional use of reading and writing. Nowadays, being literate in the 21st century involves many aspects, and media literacy indisputably takes an important role in creating a more literate nation [3].

The Council of Europe passed a resolution on media literacy back in 1989, and the last revision was made in 2019 , and in its fifth paragraph, it says "Media education should address all members of the public.
It should start at school and continue as part of a lifelong learning process, aiming to enable all individuals to exploit the potential of media for access to culture, entertainment, learning and intercultural dialogue; to help them acquire a critical approach to media as regards both quality and accuracy of content, to develop their digital skills and knowledge of existing protection tools; and to improve their online behaviour." [4].

The explanation given in the revised version clearly illustrates the variety of aspects media literacy includes, and how complex it is. It also implies that the task of schools and educational institutions surpasses a traditional perception of literacy, and that the issue of media literacy should be approached in a systematic way within the institutional framework.

As a part of the reformed system of education, media literacy was introduced as an optional subject in grammar schools in 2018, and the legal documents regulating education in the Republic of Serbia define media literacy, along with information literacy, as an obligatory competence to develop among primary and secondary school students through all subjects [1]. However, according to the research done by the Faculty of Philosophy of the University of Niš, in cooperation with the Media and Reform Centre, the level of media literacy among Serbian students is poor, and teachers usually lack knowledge and training in the field [5]. The amount of information students are exposed to on a daily basis is enormous, and the use of the Internet and social media allow them not only to consume, but also to upload and share information, which makes the issue of media literacy even more relevant.

\section{MEDIALITERACY AND ITS CORE CONCEPTS}

Today, the notion of literacy is much wider, and it encompasses different perspectives - it is cultural, critical, transformative and creative [6], and all these make the key elements of media literacy.

Media literacy can be explained as a complex ability comprising a set of various skills. Being media literate means being able to access information, read and analyse it critically, evaluate its content, and, finally, create one's own information based on the received set of data. It is complementary to information literacy, and both literacies came into the focus of worldwide attention with the introduction of the global curriculum devised by the UNESCO [7]. The skills we use while processing media input are not restricted to media literacy, but are 
developed within various contexts and daily situations, and, therefore, they can be enhanced through strategies employed in different situations.

In formal terms, media literacy is defined as "a set of perspectives that we actively use to expose ourselves to the mass media to interpret the meaning of the message we encounter" [8]. One of the main features of media literacy is that it is multidimensional, ie., it is characterised by a variety of different perspectives, which makes the task of teaching media literacy a complex pedagogical issue demanding a careful and well-planned approach.

One of the starting points in studying and tackling the issue of media literacy is a proper understanding of its key concepts, and what they involve. These concepts can serve as guiding principles to rely on while developing medial literacy skills, and due to their straightforward and clear definitions, they can compose a helpful framework within which we can teach media literacy in school. It has also been emphasised that knowing and understanding media literacy key concepts can help young people "make sense of life in a media-saturated age" [9].

The first media literacy concept states that all media are constructs, meaning that the message we receive was carefully planned and created by someone, who had some reason and intention for creating it at a certain time and place. Being media literate means being able to deconstruct this message and get its real meaning. The second concept refers to linguistic content and visual aspect of a message, i.e., what language and visual devices are used in order to convey the message. The third principle which needs to be taken into consideration is the way how different people perceive the same message, which means that being aware of different perceptions opens different perspectives on the same piece of information. The fourth concept is also crucial because it casts light on values and points of views represented in a certain message. Being able to decipher what types of messages are communicated, and what the lifestyles and values involved are, implies having a higher-order critical thinking skills. All media messages are created with a certain intent, and the fifth core concept states the importance of recognising the purpose of the constructed message [10].

All the above mentioned concepts imply the following key aspects we need to consider while endeavouring to develop media literacy and critical thinking skills: the authorship of the media message, its format (linguistic and visual/ auditory), what the aimed audience is, the content of the message, and its purpose.

\section{PROMOTING MEDIA LITERACY IN THE CLASSROOM}

Resulting from inevitable effects of media on all aspects of human endeavour, school systems and educational institutions around the world have started to consider teaching media literacy as an inseparable part of the official school curriculum. Finland was the first country in Europe to introduce media literacy systematically into education in the early seventies, and more than a decade took other European countries to follow the example [11].

The importance of specifying the objectives of media-literacy-based classes is emphasised when it comes to incorporating media literacy content into the syllabus of specific subjects [11]. The starting point for implementation of the key principles in the syllabus and promoting media literacy in the classes involves the learners' needs and learning rationale lying behind a specific subject. A careful planning and lessons designed in alignment with both the curriculum and its objectives and the main principles of media literacy can contribute to a better organisation of lessons whose aim is to promote media literacy and critical skills development.

\section{PROJECT-BASED MEDIA LITERACY TEACHING}

Due to the fact that media literacy is complex by its nature and characterised by a variety of aspects, the model of project-oriented organisation of classes provides an excellent framework for the full potential of the development of students' media literacy and critical thinking skills.

Regardless the framework and the subject being taught at school, the method relying on the projectbased teaching and learning has always aimed at engaging students in a meaningful and real-life manner [12].

Project-based teaching represents one of the innovative teaching models which has existed for centuries in educational contexts, but gained in its relevance a few decades ago, when the necessity of incorporating the principles of project-based teaching into the school system became observable in various regulations and education-related laws. Project-based teaching is defined as an active teaching method whose purpose is to connect the content studied within various school subjects, with the aim to enhance various competences, skills and literacies [1]. 
The reformed programmes also introduce projectbased teaching as a model wherein students have the opportunity to conduct some research and investigate a given issue through an interdisciplinary approach.

In an educational context, like the one above described and officially prescribed by regulations and laws, media literacy can be developed through projectoriented classes in all subjects. This work reports on one project conducted among secondary school students, in English classes, which relies on the core media literacy principles.

\section{THE DESCRIPTION OF THE PROJECT AND ITS RATIONALE}

The project was devised for secondary school students, and approximately 270 seventeen and eighteen year old students took part in it. The project was incorporated in the syllabus and comprised seven 45 -minute classes. The main aim of the project was to help students understand the main principles of media literacy, and learn how to analyse and evaluate media products using the five core concepts of media literacy. Through the analysis of popular culture, the students were introduced into its scope and nature, and were scaffolded to develop their analytical and critical thinking skills. Another important aim underlying the project was to make students aware of the scope and impact of popular culture, and to support them to be smart consumers of popular culture on a daily basis.

The reason why popular culture was chosen as a resource for promoting media literacy skills lies in the fact that students are exposed to various aspects of popular culture and consume it on a daily basis, using different channels of reception, without being fully aware of its impact on their lives. Furthermore, they already have some knowledge and a big interest in it, so the very source of investigation was motivating for the students, and, it made them more comfortable to work on and analyse material which had some relevance and value for them. The topic was chosen according to the students' needs, with the main aim to help students develop media literacy and critical thinking skills. The main rationale lying behind this choice was to empower students with adaptable set of skills they can apply in analysing any type of information or media input.

The project consisted of seven 45 minute periods: one preparatory and introductory lesson, one lesson providing theoretical background on media literacy, two lessons with students working on their projects in groups of 4, and three lessons with students presenting and evaluating their projects.

The students went through a training session about media literacy and popular culture, and were presented with theoretical background to the issue and were given instructions how to use the five core question framework to analyse some media products. After the preparatory stage, and equipped with necessary input for their independent work in groups, the students were involved in the process of accessing, analysing and evaluating a media product on popular culture chosen by the students themselves. They created their own product which reflected the whole learning process, providing reasons to justify their choice of popular culture in terns of type, values and impact on young people.

When the students' works on the projects were over, the phase of presentation followed, and the students presented their works in front of the whole class, and the most successful ones were exhibited for the whole school. The project products were in different forms PPT presentations, posters, or oral presentations with no visual support - and were chosen by the students themselves.

\section{THE EVALUATION OF THE PROJECT AND ITS RESULTS}

The important aspect of the whole project was the phase of a three-sided evaluation - students self-assessed their own contribution to the success of their group, peer assessment took a significant role in the evaluation process, and, finally, the teacher made her own evaluation sheet composed of rubrics referring to the application of media literacy principles in students' works.

The evaluation provided by the students has affective value and reveals how they felt during the whole process of preparation and participation in this project, and what their own contribution to the final product was. The answers they provided contained positive attitudes to the whole experience, and the students found project-based teaching and learning motivating and engaging, describing it with the words/ phrases such as "fun", "creative", "different", "motivating", "interesting", "working together", "relying on each other".

The rubrics that the teacher devised for the evaluation of students' works contained questions referring to the main objectives of the project and to what degree they were reached. Since the project was realised through a series of 45 minute lessons delivered in 9 classes/ groups (each group comprising approximately 
30 students), there were 63 different groups working on different projects. The evaluation sheet the teacher used contained 6 rubrics which assessed to what degree the students applied the core media literacy principles, and one question assessed how successful they were in defending the reasons for choosing a certain pop culture media product.

All questions from the teacher's evaluation sheet were structured in the same way, starting with "To what extent did the students apply the principle of ...", and the 4-point scale was used to assess the achievement of the students' projects, 1 being the least favourable, and 4 the most successful outcome.

The analysis of the evaluation sheets shows that the majority of the students (over $80 \%$ ) were able to identify the author of the media product they analysed, namely, who created the message, where and when it was produced. Another very successful outcome relates to the format of the message and the students could formulate the techniques used to draw the audience's attention rather successfully. What strikes as an encouraging result of the students' work on the task of analysing a piece of popular culture product is the way they tackled other core principles which demand a more thorough reading and analysis, with the application of critical thinking approach and a subtle interpretation of the messages. More than $70 \%$ of the students showed a high degree of awareness related to the intention of the creator of the message, different interpretations by different audiences, and the very content of the media product. Even the most demanding task related to the identification of lifestyles, values and points of view was tackled by over $40 \%$ of the students, who provided some answers related to these issues.

All these results show that the students were aware of the core medial literacy principles and the majority of them incorporated them in their analysis of the pop media products they had chosen.

The last rubric from the evaluation sheet referred to the reasons why the students opted for a certain pop culture product, and all groups provided some answer to this question. However, the quality of their explanations vary from a very detailed, supported by sound arguments, and well illustrated by examples, to those that were just mentioned with rather vague and superficial explanations, such as "because I like it", or "because many young people watch it", without any critical insight why it is relevant for discussion and analysis.

The analysis of the students' self and peer evaluation, as well as the teachers' evaluation sheets and rubrics shows that the main objectives of the project were achieved: the students could identify the scope and nature of popular culture; they learned how to analyse and evaluate a media product using five core concepts of media literacy; the active students' involvement enhanced their analytical and critical thinking skills; working as members of teams helped the students improve their communication and collaboration skills.

However, the results have been analysed and discussed through group work, not individual achievements of each student, and they should be approached accordingly. It implies that the percentage of the achieved objectives per student could be smaller, but since the aim of the project was to realise the whole project on media literacy through work group, individual achievement was not prioritised in the process of evaluation.

\section{PEDAGOGICAL IMPLICATIONS}

The results of the project conducted among secondary school students, who are susceptible to consuming a variety of media products to a large extent, on a daily basis, show that a carefully planned organisation of the teaching process, wherein the students' needs as well as complex aspects of the modern teaching paradigm are taken into consideration, can enhance students' skills and literacies, among which media literacy and critical thinking skills take a significant place.

Incorporating relevant topics on media literacy into the syllabus, and applying those teaching methods which are successful for their realisation, help students be not only wise consumers of media products but also responsible producers of various messages delivered and shared on numerous media platforms. When students get a hands-on experience, the knowledge they gain is more functional and applicable in a variety of contexts, and, therefore, more stable and longer-lasting, equipping students with skills for lifelong learning and managing in the world saturated with media production and consumption.

The inquiry process makes students active participants in the process of learning, wherein they take responsibility over their own learning, and, thus, learn how to be more responsible and independent, while the teachers take the guiding and supporting role in the teaching and learning process.

Teaching media literacy through project-oriented lessons creates the environment wherein integrated approach can reach its full potential and allow students to learn a certain content through different scientific areas. 
The use of five core media literacy principles can serve as a replicable model, or a framework for the analysis of any information, media product or input in any format, which can be reinforced and repeated in many subjects and at all educational levels, thus helping students internalise all these principles and apply them in any real life situation connected with any kind of media consumption and production.

\section{CONCLUSION}

The notion of media literacy goes beyond the media studies and media education [6], making the importance of incorporating media literacy into a curriculum even more compelling - by doing so we help learners gain lifelong skills which can be effectively employed outside the classroom, in a real world.

This paper focused on a project which was organised and delivered as a part of the curriculum, incorporating the topics of "media" and "popular culture", and delivered through project-oriented classes. This organisation of lessons encompasses various aspects of the curriculum - the topics, innovative teaching methods, skills and competences, with the focus on media literacy and its main tenets.

The aim of the described project was to motivate students to reflect upon popular culture critically, and to be aware of their own media diet. Pertaining to the exploration of the topic of popular culture, students were encouraged to think in the direction of being smart and responsible users and creators instead of being passive consumers of everything they see, hear and read about.

The main goal of the described project was to help students approach media inputs critically, with the application of five core concepts whilst selecting, analysing and evaluating a certain media product. The analysis of the whole project, based on the evaluation done by the students and the teacher shows that a project-based lesson organisation, relying on students' needs and interests, creates a supportive and engaging environment for qualitative and functional learning. Research method, as an integral part of project-based method is characterised by the the development of cognitive abilities and skills, and the process brings about results which can be applied [13]. The analysis of the teacher's evaluation sheet rubrics shows that a carefully planned and organsied lessons can develop students' media literacy and critical thinking skills.
Although the importance of media literacy is emphasised in official documents which regulate modern Serbian educational framework, media literacy is still in its infancy, and the real relevance is still to be discovered within all subjects and curricula.

\section{REFERENCES}

[1] S. Glasnik, Zakon o osnovama sistema obrazovanja $i$ vaspitanja. Službeni glasnik Republike Srbije, br. 88/2017, 27/2018 -dr. Zakon, 10/2019, 27/2018, 2017.

[2] V, Schmidt and P. L. Thomas, $21^{\text {st }}$ Century Literacy: If We Are Scripted, Are We Literate? Furman University: Springer, 2009.

[3] V, Wolf,and S. Gottwald. Tales of Literacy for the $21^{\text {st }}$ Century Literacy. Oxford: Oxford University Press, 2016.

[4] Media Education on New Media Environment. Parliamentary Assembly. Committee on Culture, Science, Education and Media, 2019.

[5] Istraživanje o medijskoj pismenosti. Univerzitet u Nišu. Filozofski fakultet. Media \& Reforms. Centar Niš, 2016. Available: http://mirc.rs/wp-content/ uploads/2016/12/Istrazivanje-MEDIJSKA-PISMENOST-MRCN.pdf.

[6] A, Burn and J. Durran. Media Literacy in Schools: Practice, Production and Progression. London: Paul Chapman Publishing.,2007.

[7] B. S. Abreu, Teaching Media Literacy. Chicago: ALA Neal-Schuman, 2019.

[8] W. J. Potter, Media Literacy. Thousand Oaks: Sage Publications, Inc, 2008.

[9] M. Hoechsmann and S. R. Poynt. Media Literacies: A Critical Introduction.. Malden, MA: Wiley-Blackwell, 2012.

[10] Center for Media Literacy. Available: https://www. medialit.org/reading-room/10-benefits-media-literacyeducation

[11] R. Kubey, Media Literacy in the Information Age. Current Perspectives. London: Transaction Publishers, 1997.

[12] P.C. Blumenfeld, E. Soloway, et all, "Motivating Project-Based Learning: Sustaining the Doing, Supporting the Learning," in Educational Psychologist, 26 (3\&4), p.p. 369-398, 1991.

[13] S. J, Krajcik and N. Shin, "Project-Based Learning," in The Cambridge Handbook of the Learning Sciences, R. K. Sawyer, R. K, Ed. New York: Cambridge University Press, 2014, pp. 275-298. 